\title{
Silicone microreactors for the photocatalytic generation of
}

\section{hydrogen}

Alejandra Castedo ${ }^{1,2}$, Ernest Mendoza ${ }^{2}$, Inmaculada Angurell ${ }^{3}$, Jordi Llorca ${ }^{1,2, *}$

${ }^{1}$ Institute of Energy Technologies, Universitat Politècnica de Catalunya, Diagonal 647, 08028 Barcelona, Spain.

${ }^{2}$ Centre for Research in Nanoengineering, Universitat Politècnica de Catalunya, Pascual i Vila 15, 08028, Barcelona, Spain.

${ }^{3}$ Department of Inorganic Chemistry, Universitat de Barcelona, Martí i Franquès 1, 08028 Barcelona, Spain.

"Corresponding author:

Prof. Jordi Llorca

Institut de Tècniques Energètiques,

Universitat Politècnica de Catalunya

Av. Diagonal 647, Ed. ETSEIB

08028 Barcelona, Spain

Tel.: (+34) 934011708

e-mail: jordi.llorca@upc.edu 


\section{Abstract}

A silicone microreactor with $500 \mu$ m-width microchannels coated with a $\mathrm{Au} / \mathrm{TiO}_{2}$ photocatalyst was manufactured and tested for the photocatalytic generation of hydrogen from gaseous water-ethanol mixtures under dynamic conditions. The manufacture of the microreactor included the fabrication of a polylactic acid (PLA) mold with a 3D printer and casting with polydimethylsiloxane (PDMS) prepolymer. After curing, the silicone microreactor was peeled off and the microchannels were coated with a $\mathrm{Au} / \mathrm{TiO}_{2}$ photocatalyst prepared by impregnation of preformed $\mathrm{Au}$ nanoparticles over $\mathrm{TiO}_{2}$, and sealed with a thin silicone cover. The microreactor was tested at room temperature and atmospheric pressure under different operational conditions (photon irradiance, residence time, photocatalyst loading, and waterethanol ratio). Hydrogen production rates of $5.4 \mathrm{NmL} \cdot \mathrm{W}^{-1} \cdot \mathrm{h}^{-1}$ were measured at a residence time of $0.35 \mathrm{~s}$ using a $\mathrm{H}_{2} \mathrm{O}: \mathrm{C}_{2} \mathrm{H}_{5} \mathrm{OH}$ molar ratio of 9:1, a photocatalyst load of $1.2 \mathrm{mg} \cdot \mathrm{cm}^{-2}$ and a UV irradiance $(365 \mathrm{~nm})$ of $1.5 \mathrm{~mW} \cdot \mathrm{cm}^{-2}$ achieving an apparent quantum efficiency of $9.2 \%$. The photogeneration of hydrogen with commercial bioethanol was also tested. A long-term photocatalytic test of two days revealed a stable hydrogen photoproduction rate. The use of silicone microreactors represents an attractive and customizable solution for conducting photochemical reactions for producing hydrogen at low cost.

Keywords: microreactor, silicone, 3D printer, photocatalysis, $\mathrm{H}_{2}$ production. 


\section{Introduction}

Heterogeneous photocatalysis is a well-known catalytic process with many applications in water treatment and air purification [1,2]. Recently, it has also been proposed as an interesting route for the production of renewable hydrogen from water and organic compounds for energy applications [3,4], which has boosted a renewed interest in the formulation of photocatalysts as well as in the development of new photocatalytic reactor concepts. Semiconductor photocatalysis has received much attention over the past few decades as a promising solution to capture and convert the energy supplied by the Sun (light) into chemical energy stored in the $\mathrm{H}-\mathrm{H}$ bond. Among the various semiconductor photocatalysts tested so far, $\mathrm{TiO}_{2}$-based systems (anatase or rutile-anatase mixtures) seem to be the most promising, due to their availability, high chemical stability, non-toxicity and low cost. Unfortunately, $\mathrm{TiO}_{2}$ is inefficient for hydrogen generation due to low activity as a consequence of its wide bandgap (3.0-3.2 eV), so it is necessary to modify the surface of $\mathrm{TiO}_{2}$ to enhance its photon efficiency (apparent quantum yield). This can be done by decorating the $\mathrm{TiO}_{2}$ particles with metal nanoparticles that can accept the photoexcited electrons from the conduction band of the semiconductor, and/or by adding sacrificial agents that are oxidized by the holes created in the valence band. Ethanol is considered an excellent hole scavenger because it is readily available, easy to obtain from biomass, and safe to handle [3].

It is important to recall that the success of photocatalytic hydrogen production will be affected not only by the activity of the photocatalyst itself, but also by the effective transmission of photons to its surface. Most of the photocatalytic processes reported 
so far use agitated slurry reactors, which suffer from poor photon transfer from the external photon source to the photocatalyst particles in suspension. In addition, the photocatalyst particles must be recovered downstream using centrifuges and filters. Several solutions have been proposed to overcome the photon transfer limitations without sacrificing mass transport, such as the use of optical fibers inside photocatalytic honeycombs [5-7] and conventional optofluidic devices made out of quartz or Pyrex with microchannels made by either micro-milling, etching processes or laser ablation $[8,9]$. In these devices, in addition to increasing reaction rates by improving both mass and optical transfer efficiencies, the photocatalyst is immobilized on the reactor walls and no recovery is necessary. Photocatalytic microreactors with immobilized $\mathrm{TiO}_{2}$ catalyst have already proven to be a highly effective tool for the synthesis of fine chemicals and for the selective cleavage of peptides and proteins $[10,11]$. However, these solutions are expensive and difficult to implement. In this work, we report on the fabrication of silicone microreactors containing microchannels by replica molding with an immobilized $\mathrm{Au} / \mathrm{TiO}_{2}$ photocatalyst for producing hydrogen from water-ethanol mixtures. This method provides a rapid, cheap, and customizable manufacture of microreactors with easy scale up and rapid prototyping for the continuous photoproduction of hydrogen.

\section{Experimental methods}

\subsection{Fabrication of the photocatalytic silicone microreactors}

The silicone microreactors were fabricated by casting polydimethylsiloxane (PDMS) prepolymer over a polylactic acid (PLA) mold manufactured with a 3D printer. Figure 
1 shows a scheme of the procedure used. Google SketchUp and Slic3r software were used for the design of the PLA mold. The primary advantage of this technique is that almost any shape or geometric feature can be created. In our case, the mold consisted of nine rods of $500 \mu \mathrm{m}$ (width) $\times 1 \mathrm{~mm}$ (depth) $\times 47 \mathrm{~mm}$ (length), with a total volume of $0.21 \mathrm{~cm}^{3}$, and two collectors to facilitate gas distribution as shown in Figure 1. The molds were fabricated with a replicating rapid prototyper RepRap BCN3D printer with PLA extruded at $210-220^{\circ} \mathrm{C}$. The printing time for each mold was ca. 8 minutes. In order to obtain the silicone microreactors, a mixture of PDMS prepolymer (elastomer) and curing agent (cross-linker) Sylgard 184 (Dow Corning) was prepared with a ratio 10:1 (w/w) and degassed. The mixture was poured onto the PLA mold and the assembly was cured at $100^{\circ} \mathrm{C}$ for 45 min. After curing, the resulting silicone microreactor was peeled off from the mold and appropriate connections were inserted. The same procedure was used to fabricate the cover (thickness of ca. $400 \mu \mathrm{m}$ ), but in this case PDMS was poured on a flat glass surface. PDMS is optically transparent down to $240 \mathrm{~nm}$.

The $\mathrm{Au} / \mathrm{TiO}_{2}$ photocatalyst was deposited on the walls of the silicone microchannels from a sonicated ethanol suspension containing the photocatalyst particles. To attain a proper immobilization, a corona discharge plasma treatment was previously applied over the microchannels to produce a silanol-terminated surface. The photocatalyst was prepared by incipient wetness impregnation of pre-formed Au nanoparticles dispersed in toluene over commercial $\mathrm{TiO}_{2}$ (Degussa P90; ca. $90 \mathrm{~m}^{2} \cdot \mathrm{g}^{-1}$ ), with a metal loading of 1.8 wt.\% with respect to $\mathrm{TiO}_{2}$. This value was selected following previous studies, where an optimum Au loading of $1-2 \mathrm{wt} . \%$ was found $[6,12,13]$. The pre-formed Au nanoparticles consisted of metallic Au cores covered by a protective 
shell of dodecanethiol and were prepared as reported previously [7]. Briefly, $\mathrm{AuCl}_{4}^{-}$ was first transferred from aqueous $\mathrm{HAuCl}_{4}$ solution $(40 \mathrm{mM})$ to toluene solution using tetraoctylammonium bromide as a phase transfer reagent. Dodecanethiol was then added to the solution at a 1:1 molar ratio of dodecanethiol:Au, and an excess of aqueous $\mathrm{NaBH}_{4}$ was slowly added to reduce the metal salt. The resulting dodecanethiol-capped metallic nanoparticles were dried and cleaned using ethanol. The photocatalyst was calcined at $673 \mathrm{~K}$ for $2 \mathrm{~h}\left(2 \mathrm{~K} \cdot \mathrm{min}^{-1}\right)$ to eliminate the protective shell and to assure a good contact and electronic interaction between the $\mathrm{Au}$ nanoparticles and $\mathrm{TiO}_{2}$ support. This temperature was selected following the study reported in [14]. No further activation was required for the photocatalytic experiments. Different photocatalyst loadings were tested, namely $0.5,1.2,2.4$ and $7.1 \mathrm{mg} \cdot \mathrm{cm}^{-2}$ (total weight of catalyst with respect to the surface exposed by the microchannels). Finally, after immobilization of the photocatalyst over the microchannels, the silicone microreactor was sealed with the silicone cover using a corona plasma treatment (BD-20AC Electro-Technic Products) for 2 minutes over both pieces, which were pressed together and baked overnight at $75 \stackrel{\circ}{\circ}$ (Figure $2 \mathrm{~A})$.

\subsection{Characterization}

The photocatalyst was characterized by X-ray diffraction (XRD), UV-Visible reflectance spectroscopy, scanning electron microscopy (SEM), transmission electron microscopy (TEM) and X-ray photoelectron spectroscopy (XPS). The microchannels and the deposition of the photocatalyst on their walls were observed before and after the photocatalytic test by optical microscopy. XRD measurements were carried out with a Bruker D8 diffractometer with CuKa radiation and a graphite 
monochromator. The patterns were collected between $5^{\circ}$ and $80^{\circ}$ of $2 \Theta$ with a step width of $0.02^{\circ}$ and a step time of $1 \mathrm{~s}$. UV-Vis spectra were collected with a Shimadzu UV3600 UV-Vis-NIR spectrometer equipped with an integrating sphere. SEM was performed with a Zeiss Neon40 Crossbeam Station equipped with a field emission electron source. High resolution transmission electron microscopy (HRTEM) was carried out using a JEOL JEM 2010F instrument equipped with a field emission source at an accelerating voltage of $200 \mathrm{kV}$. Powders were suspended in methanol under ultrasonic treatment before they were deposited on holey carbon-coated grids. The point-to-point resolution achieved was $0.19 \mathrm{~nm}$ and the resolution between lines was $0.14 \mathrm{~nm}$. A minimum of 200 particles were measured for particle size determination. The size limit for the detection of nanoparticles on the support was about $1 \mathrm{~nm}$. The average particle diameter was calculated from the mean diameter frequency distribution with the formula: $d=\sum n_{i} d_{i} / \Sigma n_{i}$, where $n_{i}$ is the number of particles with particle diameter $d_{i}$ in a certain range. High-angle annular dark-field imaging (HAADF) was carried out in STEM mode with a Tecnai G2 F20 S-TWIN transmission electron microscope equipped with a field emission electron source operated at $200 \mathrm{kV}$ and with a point-to-point resolution of $0.24 \mathrm{~nm}$. X-ray photoelectron spectroscopy (XPS) was performed on a SPECS system equipped with an Al anode XR50 source operating at $150 \mathrm{~mW}$ and a Phoibos 150 MCD-9 detector. The pass energy of the hemispherical analyzer was set at $25 \mathrm{eV}$ and the energy step was set at $0.1 \mathrm{eV}$. The binding energy $(\mathrm{BE})$ values were referred to the $\mathrm{C}$ 1s peak at $284.8 \mathrm{eV}$. 


\subsection{Photocatalytic experiments}

Photocatalytic experiments were carried out at atmospheric pressure and room temperature under dynamic conditions. An argon stream was bubbled into a saturator containing water and/or ethanol or bioethanol and the gaseous mixture was directly introduced into the microreactor, which was previously purged with Ar. Pure ethanol ( $>99.9 \%$ purity) was supplied by Scharlau, whereas commercial bioethanol was obtained from Deulep (France, ca. 96\% purity) and Bioetanol de la Mancha (Spain, $>90 \%$ purity, $5 \mathrm{ppm}$ sulfur). Two high efficacy LEDs were used to illuminate the microreactor at $365 \pm 2 \mathrm{~nm}$ (LED Engin LZ1-10U600). The illumination was varied between 0 and $23 \mathrm{~mW} \cdot \mathrm{cm}^{-2}$. Light irradiation was measured directly in the microreactor with a UV-A radiation monitor from Solar Light Co. The outlet of the microreactor was connected to an Agilent 490 Micro gas chromatograph equipped with MS $5 \AA$, Plot $U$ and Stabilwax columns for a complete and direct analysis of products. Four measurements were made at each condition (lasting about $85 \mathrm{~min}$ ) with excellent reproducibility. Photocatalytic studies were conducted in gas phase by using water:ethanol mixtures of 100:0, 99:1, 90:10, 80:20, 65:35, $50: 50$ and 0:100 (molar basis) at residence times of 0.56 and $0.35 \mathrm{~s}$ (GHSV=6500 and $10200 \mathrm{~h}^{-1}$, respectively).

\section{Results and discussion}

\subsection{Characterization of the photocatalyst and the microreactor}


Figure 2 shows a general picture of a silicone microreactor loaded with the $\mathrm{Au} / \mathrm{TiO}_{2}$ photocatalyst (Figure 2A). The deposition of the photocatalyst was successful and the coating was homogeneous as evidenced by optical microscopy (Figure 2B). XRD profiles showed the presence of both anatase and rutile with an anatase:rutile ratio of $80: 20$, as determined according to the method described in [15]. The morphology of the catalyst layer was studied by SEM, and a very homogeneous distribution of $\mathrm{TiO}_{2}$ nanoparticles of about 15-20 nm in size was obtained (Figure 3A). The microstructure of the photocatalyst was investigated by bright-field TEM, high resolution TEM (HRTEM), STEM under high angle annular dark field mode (HAADF), and EDX analyses. Figures $3 \mathrm{~B}$ and $3 \mathrm{C}$ are representative images of the photocatalyst and correspond to TEM and STEM images recorded over the same area, respectively. An excellent distribution of individual $\mathrm{TiO}_{2}$ crystallites is seen along with the presence of small Au nanoparticles (which appear in dark contrast in TEM and bright contrast in STEM). The mean particle size of the Au nanoparticles is about $4 \mathrm{~nm}$. This is slightly larger than the size of Au nanoparticles capped with dodecanethiol in the precursor dispersion as a result of the calcination treatment, in accordance with [14]. The homogeneity in size and good dispersion of the Au nanoparticles deserve to be highlighted, which are a direct consequence of the preparation method employed. The sample showed a localized surface plasmon resonance (LSPR) at about $567 \mathrm{~nm}$ in the UV-Vis reflectance spectra, which is fairly similar to values reported in the literature for Au nanoparticles measuring 3-5 nm supported on anatase [12]. Figure 3D corresponds to a representative HRTEM image, showing lattice fringes corresponding to the (101) crystallographic planes of $\mathrm{TiO}_{2}$ (anatase) at $3.52 \AA$ and to the (200) crystallographic planes of metallic $A u$ at $2.04 \AA$. There is an intimate contact between the $\mathrm{Au}$ nanoparticles and the $\mathrm{TiO}_{2}$ support particles. A 
representative EDX spectrum corresponding to the Au nanoparticles depicted in Figure $3 \mathrm{E}$ is provided in Figure 3F. Signals of $\mathrm{Ti}$ and $\mathrm{O}$ from $\mathrm{TiO}_{2}$ and signals of $\mathrm{Au}$ are identified (the $\mathrm{Cu}$ signals are due to the $\mathrm{Cu}$ grid used for TEM). In accordance to the HRTEM results, the binding energies recorded at $83.9 \mathrm{eV}\left(\mathrm{Au} 4 \mathrm{f}_{7 / 2}\right)$ and $87.4 \mathrm{eV}$ $\left(A u 4 f_{5 / 2}\right)$ in the $A u 4 f$ core-level photoelectron spectrum indicated that metallic $\mathrm{Au}$ was the only gold species on the near surface region of the photocatalyst.

\subsection{Photocatalytic tests}

A series of experiments were performed at room temperature over a silicone microreactor loaded with $2.4 \mathrm{mg} \cdot \mathrm{cm}^{-2}$ of $\mathrm{Au} / \mathrm{TiO}_{2}$ photocatalyst under different waterethanol gaseous mixtures and irradiation intensities at a residence time of $0.35 \mathrm{~s}$ $\left(\mathrm{GHSV}=10200 \mathrm{~h}^{-1}\right.$ ) (Figure 4). In addition, blank experiments with bare $\mathrm{TiO}_{2}$ were also carried out for comparison. The only products detected were hydrogen and acetaldehyde in a nearly stoichiometric proportion when ethanol was present in the reaction mixture, thus confirming the overall reaction process as $\mathrm{CH}_{3} \mathrm{CH}_{2} \mathrm{OH} \rightarrow \mathrm{CH}_{3} \mathrm{CHO}+\mathrm{H}_{2}$, in accordance with previous works reported in the literature [3]. In all cases, steady state was rapidly achieved. As a general rule, the amount of hydrogen photogenerated increased with irradiation intensity, which means that more photons were progressively involved in the photoprocess. However, when water was absent in the reaction mixture (100\% ethanol), the photoproduction of hydrogen remained constant and was independent of irradiation intensity at values higher than $10 \mathrm{~mW} \cdot \mathrm{cm}^{-2}$. This behavior may indicate that, in the absence of water, acetaldehyde strongly adsorbs onto the photocatalyst surface, resulting in the blockage of the active sites of the photocatalyst [5]. The absence of this effect when 
water is present in the reaction mixture may be indicative of a competitive adsorption between water and acetaldehyde, which is beneficial for the progress of the photoreaction. In these cases, the photoproduction of hydrogen is approximately proportional to the square root of the incident photon intensity, which is explained in terms of competition between surface reactions and electron-hole recombination processes [6].

The photoproduction of hydrogen increased sharply as the amount of ethanol in the reaction mixture increased from 1 to $10 \%$ (Figure 4), but for ethanol concentration values between 20 and $50 \%$ the hydrogen photogeneration remained approximately constant, thus indicating that for high ethanol concentrations the reaction rate was of the apparent zero order. Therefore, taking into account the hydrogen photoproduction rate obtained using a water-ethanol gaseous mixture with $10 \%$ ethanol (molar basis) and assuming that two photons are required for producing one hydrogen molecule, the apparent quantum efficiency (AQE) was calculated from the ratio of twice the amount of $\mathrm{H}_{2}\left(\mathrm{r}_{\mathrm{H} 2}, 0.013 \mu \mathrm{mol} \mathrm{H} \mathrm{H}_{2} \cdot \mathrm{min}^{-1}\right)$ and the overall amount of photons reaching the microreactor $\left(\mathrm{N}_{\lambda}, 0.58 \mu \mathrm{mol}\right.$ photons $\cdot \mathrm{min}^{-1}$ at $\left.1.5 \mathrm{~mW} \cdot \mathrm{cm}^{-2}\right)$ using the equation $A Q E=\left(2 \cdot r_{\mathrm{H}_{2}} / \mathrm{N}_{\lambda}\right) \cdot 100$ [16]. Under these conditions the $A Q E$ value was $4.6 \%$. The efficiency of light-to-chemical energy conversion, defined as the energy stored as hydrogen $\left(\mathrm{r}_{\mathrm{H} 2} \cdot \Delta \mathrm{H}_{\mathrm{c}, \mathrm{H} 2}\right.$, where $\Delta \mathrm{H}_{\mathrm{c}, \mathrm{H} 2}$ is the heating value of hydrogen, $\left.285.8 \mathrm{~kJ} \cdot \mathrm{mol}^{-1}\right)$ divided by the incident photon energy $(3.17 \mathrm{~mW})$, is about $2 \%$. These values are comparable to other values reported in the literature for $\mathrm{M} / \mathrm{TiO}_{2}$ catalysts $[5,6,17,18]$. The silicone microreactor was also tested for direct water photosplitting (100\% water, no sacrificial agent) and, as expected, the photoproduction of hydrogen was remarkably lower (Figure 4), in accordance with previous results reported in the 
literature $[5,6]$. Analogously, the blank experiments over bare $\mathrm{TiO}_{2}$ in the absence of co-catalyst yielded considerably lower hydrogen production rates with respect to those obtained with the $\mathrm{Au} / \mathrm{TiO}_{2}$ photocatalyst under the same conditions (Figure 4).

Another series of experiments were conducted using commercial bioethanol. The hydrogen photoproduction rates obtained at different incident photon intensities and contact times are shown in Figure 5. At a given light irradiance and GHSV $=10200 \mathrm{~h}^{-1}$, the photoproduction rate of hydrogen was virtually identical between experiments performed with pure ethanol and those using different commercial bioethanols (bioethanol-1 corresponds to Deulep and bioethanol-2 corresponds to Bioetanol de la Mancha, with about $5 \mathrm{ppm}$ sulfur). This is an important result and provides direct evidence that this technology can be used in the valorization of agricultural residues for the photoproduction of hydrogen with real substrates. However, residence time had the opposite effect on hydrogen photoproduction rates at a given light irradiance in experiments performed with bioethanol as it did in those carried out using ethanol. At GHSV $=6500 \mathrm{~h}^{-1}$, the photoproduction of hydrogen was higher in the experiments performed with ethanol with respect to those carried out at GHSV $=10200 \mathrm{~h}^{-1}$ due to a longer contact time (0.56 vs. $0.35 \mathrm{~s})$. In contrast, slightly lower photoproduction of hydrogen was obtained in the experiments performed using commercial bioethanol at a longer contact time. This could be explained considering the presence of other organic compounds in commercial bioethanol (e.g. higher alcohols, phenols, aldehydes, organic acids, etc.), which at longer contact times may be strongly adsorbed on the photocatalyst surface, thus lowering its photoactivity. 
The dependence of the rate of hydrogen photoproduction on photocatalyst loading was studied at different light irradiance under a water-ethanol gaseous mixture of 90:10 (molar basis) at GHSV=10200 $\mathrm{h}^{-1}$. The results are shown in Figure 6. As expected, higher hydrogen production rates were obtained at higher photon doses, in accordance with the results presented in Figures 4 and 5 and discussed above. However, the amount of photocatalyst deposited (weight of catalyst per surface area of the microchannels in the microreactor) had a strong influence on the photoproduction rate of hydrogen. For all light irradiance values there was a maximum in photoactivity at about $1.2 \mathrm{mg} \cdot \mathrm{cm}^{-2}$. A lower photocatalyst loading value (ca. $0.5 \mathrm{mg} \cdot \mathrm{cm}^{-2}$ ) resulted in lower hydrogen photogeneration rates, whereas higher photocatalyst loadings (ca. $2.4 \mathrm{mg} \cdot \mathrm{cm}^{-2}$ and higher) were ineffective at increasing the photoactivity. This is explained in terms of light penetration in the photocatalyst layer deposited onto the surface of the microchannels. Achieving optimum light utilization involves balancing the photon dose with the photocatalyst layer thickness. In our case, at a photocatalyst loading of $0.5 \mathrm{mg} \cdot \mathrm{cm}^{-2}$, the photon dose is sufficient for the photocatalytic process taking into account the photocatalyst layer thickness and, consequently, the hydrogen photoproduction rate on a photocatalyst weight basis is kept low. At the optimum photocatalyst loading, the interaction of photons with the photocatalyst is maximized and the highest hydrogen photoproduction rates are obtained. The maximum AQE recorded with the optimum photocatalyst loading is $9.2 \%$ under $1.5 \mathrm{~mW} \cdot \mathrm{cm}^{-2}$ and $10 \%$ ethanol. It is interesting to note that the increase in the hydrogen photoproduction rate is not exactly proportional to the increase in light irradiance because, at increasing photon dose, more photocatalyst can be progressively used. For photocatalyst loadings of ca. $2.4 \mathrm{mg} \cdot \mathrm{cm}^{-2}$ and higher there is 
an excess of photocatalyst with respect to the photon penetration depth of and the relative hydrogen photoproduction rates decrease accordingly.

Finally, a stability test was conducted over a silicone microreactor for two days at 6 $\mathrm{mW} \cdot \mathrm{cm}^{-2}$ by using a mixture of water and ethanol $(10 \% \mathrm{EtOH}$, molar basis) at GHSV $=10200 \mathrm{~h}^{-1}$ (Figure 7). There was an initial deactivation of about $11 \%$ during the first ca. $15 \mathrm{~h}$ and then a constant photoproduction rate of hydrogen of about 6.8 $\mu \mathrm{mol} \cdot \mathrm{min}^{-1} \cdot \mathrm{g}^{-1}$ was maintained.

The normalized hydrogen photogeneration rate obtained in the silicone photomicroreactor was $0.013 \frac{\mu m o H_{2}}{\mathrm{~min} \cdot \mathrm{mg} \cdot \mathrm{mW}}$. Using exactly the same photocatalyst and gaseous mixture $(10 \% \mathrm{EtOH}$, molar basis), the normalized hydrogen photogeneration rate obtained in an optical fiber honeycomb photoreactor was $0.032 \frac{\mu m o H_{2}}{\mathrm{~min} \cdot \mathrm{mg} \cdot \mathrm{mW}}$ [7]. The higher hydrogen photogeneration rate recorded in the optical fiber honeycomb photoreactor is a direct consequence of the improved photon transfer (all photons emitted by the fiber inside the honeycomb cells reach the photocatalyst deposited on the honeycomb walls). However, this geometry does not allow using sunlight directly, as sunlight needs first to be collected and directed to the optical fibers. The silicone photomicroreactor, although less efficient, can be directly used for light harvesting and does not have geometrical limitations.

\section{Conclusions}

The manufacture of silicone microreactors provides a new strategy for conducting photocatalytic processes aimed at the local generation of hydrogen. We have shown 
that a simple and cheap procedure based on 3D printing and PDMS polymerization can be exploited for developing novel microreactor designs and concepts. Here we have applied this technology for the first time to fabricate silicone microreactors for the photoproduction of hydrogen. We have tested a $\mathrm{Au} / \mathrm{TiO}_{2}$ photocatalyst in a silicone microreactor with $500 \mu \mathrm{m}$-width channels at ambient temperature and pressure under different gaseous water-ethanol gaseous mixtures, photocatalyst loadings, and light irradiance under dynamic conditions. A maximum apparent quantum efficiency of $4.6 \%$ has been measured for a water-ethanol mixture of $9: 1$ (molar basis) at $1.5 \mathrm{~mW} \cdot \mathrm{cm}^{-2}(365 \mathrm{~nm})$. An optimum value of $1.2 \mathrm{mg} \cdot \mathrm{cm}^{-2}$ for the photocatalyst loading has been determined to maximize light efficiency. To validate the potential interest in this technology for the valorization of agricultural residues, similar tests have been conducted with different types of commercial bioethanol and the hydrogen photoproduction rates obtained at short contact time (0.35 s) have been virtually identical to those obtained with pure ethanol. Long-term runs have shown stable performance after an initial slight deactivation.

\section{Acknowledgments}

This work has been funded through MINECO grant ENE2012-36368. J.L. is Serra Húnter Fellow and is grateful to ICREA Academia program. A.C. is grateful to MINECO for PhD grant BES-2013-065709. 


\section{References}

[1] S. Dong, J. Feng, M. Fan, Y. Pi, L. Hu, X. Han, et al., Recent developments in heterogeneous photocatalytic water treatment using visible light-responsive photocatalysts: a review, RSC Adv. 5 (2015) 14610-14630.

[2] K. Rajeshwar, M.E. Osugi, W. Chanmanee, C.R. Chenthamarakshan, M.V.B. Zanoni, P. Kajitvichyanukul, et al., Heterogeneous photocatalytic treatment of organic dyes in air and aqueous media, J. Photochem. Photobiol. C Photochem. Rev. 9 (2008) 171-192.

[3] M. Murdoch, G.I.N. Waterhouse, M. a Nadeem, J.B. Metson, M. a Keane, R.F. Howe, et al., The effect of gold loading and particle size on photocatalytic hydrogen production from ethanol over $\mathrm{Au} / \mathrm{TiO}_{2}$ nanoparticles., Nat. Chem. 3 (2011) 489-492.

[4] L.M. Gandía, G. Arzamendi, P.M. Diéguez, Renewable hydrogen technologies, Elsevier, Amsterdam, 2013.

[5] E. Taboada, I. Angurell, J. Llorca, Hydrogen photoproduction from bio-derived alcohols in an optical fiber honeycomb reactor loaded with $\mathrm{Au} / \mathrm{TiO}_{2}$, J. Photochem. Photobiol. A Chem. 281 (2014) 35-39.

[6] E. Taboada, I. Angurell, J. Llorca, Dynamic photocatalytic hydrogen production from ethanol-water mixtures in an optical fiber honeycomb reactor loaded with $\mathrm{Au} / \mathrm{TiO}_{2}$, J. Catal. 309 (2014) 460-467. 
[7] E. Bonmatí, A. Casanovas, I. Angurell, J. Llorca, Hydrogen Photoproduction from Ethanol-Water Mixtures Over Au-Cu Alloy Nanoparticles Supported on $\mathrm{TiO}_{2}$, Top. Catal. 58 (2014) 77-84.

[8] S.S. Ahsan, A. Gumus, D. Erickson, Redox mediated photocatalytic watersplitting in optofluidic microreactors, Lab Chip. 13 (2013) 409-414.

[9] K.F. Jensen, Microreaction engineering - is small better?, Chem. Eng. Sci. 56 (2001) 293-303.

[10] E.E. Coyle, M. Oelgemöller, Micro-photochemistry: photochemistry in microstructured reactors. The new photochemistry of the future?, Photochem. Photobiol. Sci. 7 (2008) 1313.

[11] D.M. Roberge, L. Ducry, N. Bieler, P. Cretton, B. Zimmermann, Microreactor Technology: A Revolution for the Fine Chemical and Pharmaceutical Industries?, Chem. Eng. Technol. 28 (2005) 318-323.

[12] V. Jovic, W.T. Chen, D. Sun-Waterhouse, M.G. Blackford, H. Idriss, G.I.N. Waterhouse, Effect of gold loading and $\mathrm{TiO}_{2}$ support composition on the activity of $\mathrm{Au} / \mathrm{TiO}_{2}$ photocatalysts for $\mathrm{H}_{2}$ production from ethanol-water mixtures, J. Catal. 305 (2013) 307-317. 
[13] G.R. Bamwenda, S. Tsubota, T. Nakamura, M. Haruta, Photoassisted hydrogen production from a water-ethanol solution: a comparison of activities of $\mathrm{Au} / \mathrm{TiO}_{2}$ and $\mathrm{Pt}_{\mathrm{TiO}}$, J. Photochem. Photobiol. A Chem. 89 (1995) 177-189.

[14] J. Llorca, M. Domínguez, C. Ledesma, R.J. Chimentão, F. Medina, J. Sueiras, et al., Propene epoxidation over $\mathrm{TiO}_{2}$-supported $\mathrm{Au}$-Cu alloy catalysts prepared from thiol-capped nanoparticles, J. Catal. 258 (2008) 187-198.

[15] X. Fu, L.A. Clark, Q. Yang, M.A. Anderson, Enhanced Photocatalytic Performance of Titania-Based binary metal-oxides: $\mathrm{TiO}_{2} / \mathrm{SiO}_{2}$ and $\mathrm{TiO}_{2} / \mathrm{ZrO}_{2}$, Environ. Sci. Technol. 30 (1996) 647-653.

[16] A. Tanaka, S. Sakaguchi, K. Hashimoto, H. Kominami, Preparation of $\mathrm{Au} / \mathrm{TiO}_{2}$ with metal cocatalysts exhibiting strong surface plasmon resonance effective for photoinduced hydrogen formation under irradiation of visible light, ACS Catal. 3 (2013) 79-85.

[17] Y.Z. Yang, C.H. Chang, H. Idriss, Photo-catalytic production of hydrogen from ethanol over $\mathrm{M} / \mathrm{TiO}_{2}$ catalysts ( $\mathrm{M}=\mathrm{Pd}$, Pt or Rh), Appl. Catal. B:Environ. 67 (2006) 217-222.

[18] K. Connelly, A.K. Wahab, H. Idriss, Photoreaction of $\mathrm{Au} / \mathrm{TiO}_{2}$ for hydrogen production from renewables: a review of the synergistic effect between anatase and rutile phases of $\mathrm{TiO}_{2}$, Mater. Renew. Sustain. Energy (2012) 1:3. 


\section{Figure legends}

Figure 1. Scheme of the fabrication steps of the silicone microreactors.

Figure 2. Picture of a silicone microreactor loaded with photocatalyst (A) and image obtained by optical microscopy of the catalytic layer deposited over a microchannel (B).

Figure 3. SEM (A), bright-field TEM (B) and STEM (C) images recorded at low magnification of the $\mathrm{Au} / \mathrm{TiO}_{2}$ photocatalyst as prepared. High resolution TEM image showing the lattice fringes of $\mathrm{TiO}_{2}$ and $\mathrm{Au}$ along with the corresponding $\mathrm{FT}$ image (D). STEM-HAADF image (E) and EDX analysis (F) recorded over an individual Au nanoparticle. The Cu signal originates from the TEM sample holder.

Figure 4. Effect of light irradiance on $\mathrm{H}_{2}$ photoproduction over a microreactor loaded with $2.4 \mathrm{mg} \cdot \mathrm{cm}^{-2}$ of $\mathrm{Au} / \mathrm{TiO}_{2}$ photocatalyst or $\mathrm{TiO}_{2}$ (blank) with different water-ethanol gaseous mixtures (molar basis). GHSV $=10200 \mathrm{~h}^{-1}$. The error bars correspond to the average of four measurements.

Figure 5. Hydrogen photoproduction rate over a microreactor loaded with $2.4 \mathrm{mg} \cdot \mathrm{cm}^{-}$

${ }^{2}$ of $\mathrm{Au} / \mathrm{TiO}_{2}$ photocatalyst with water-ethanol or water-bioethanol gaseous mixtures of 90:10 (molar basis) under different light irradiance and contact time (grey: GHSV $=10200 \mathrm{~h}^{-1}$, white: $\left.6500 \mathrm{~h}^{-1}\right)$. The error bars correspond to the average of eight measurements. 
Figure 6. Effect of photocatalyst loading on the hydrogen photoproduction rate using a water-ethanol gaseous mixture of 90:10 (molar basis) under different light irradiance at GHSV $=10200 \mathrm{~h}^{-1}$. The error bars correspond to the average of eight measurements.

Figure 7. Stability test over a microreactor loaded with $2.4 \mathrm{mg} \cdot \mathrm{cm}^{-2}$ of $\mathrm{Au} / \mathrm{TiO}_{2}$ catalyst with a water-ethanol gaseous mixture of $90: 10$ (molar basis) at $6 \mathrm{~mW} \cdot \mathrm{cm}^{-2}$ and GHSV $=10200 \mathrm{~h}^{-1}$. 

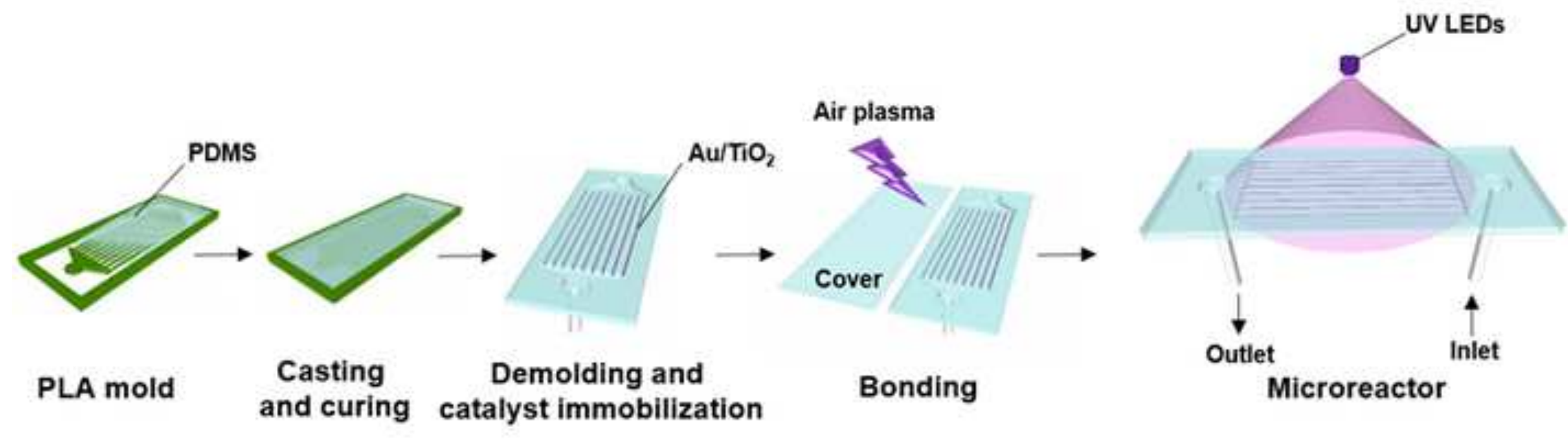


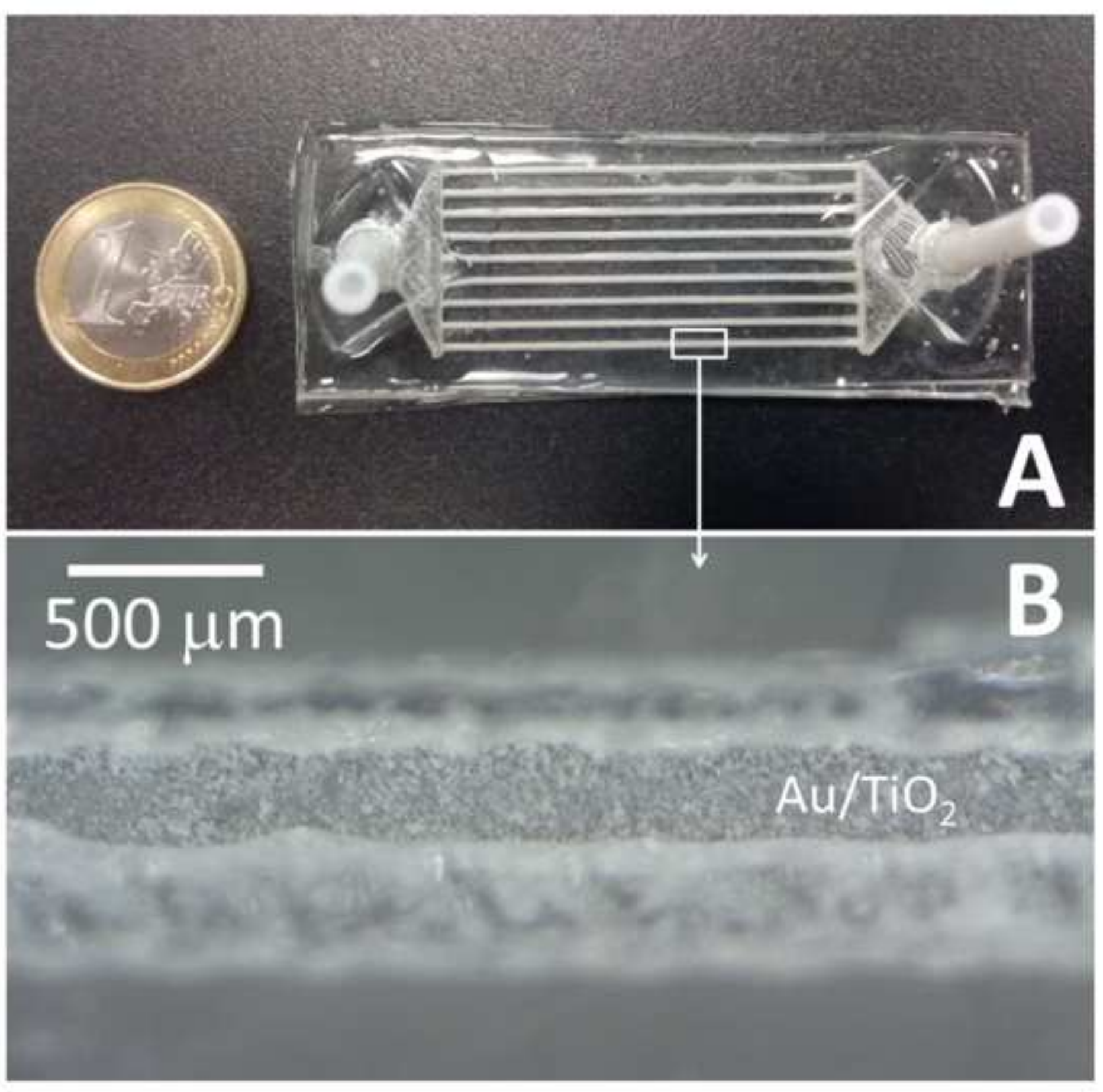

Figure 2

$500 \mu \mathrm{m}$

2

\section{Fire}

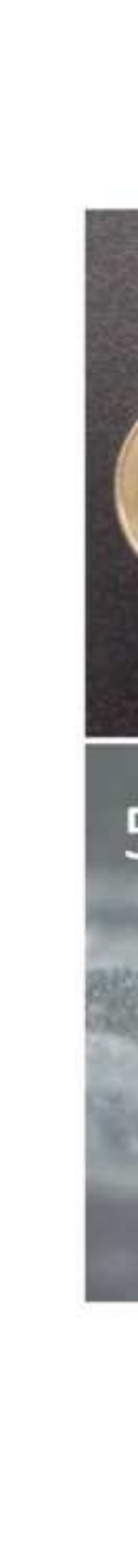

1

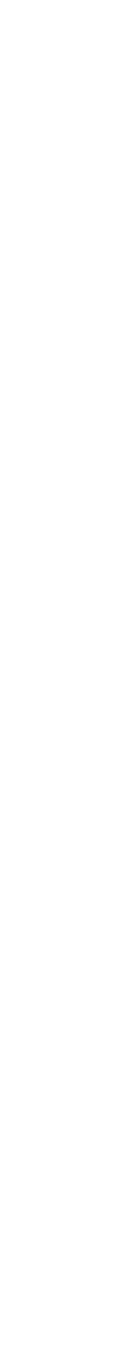



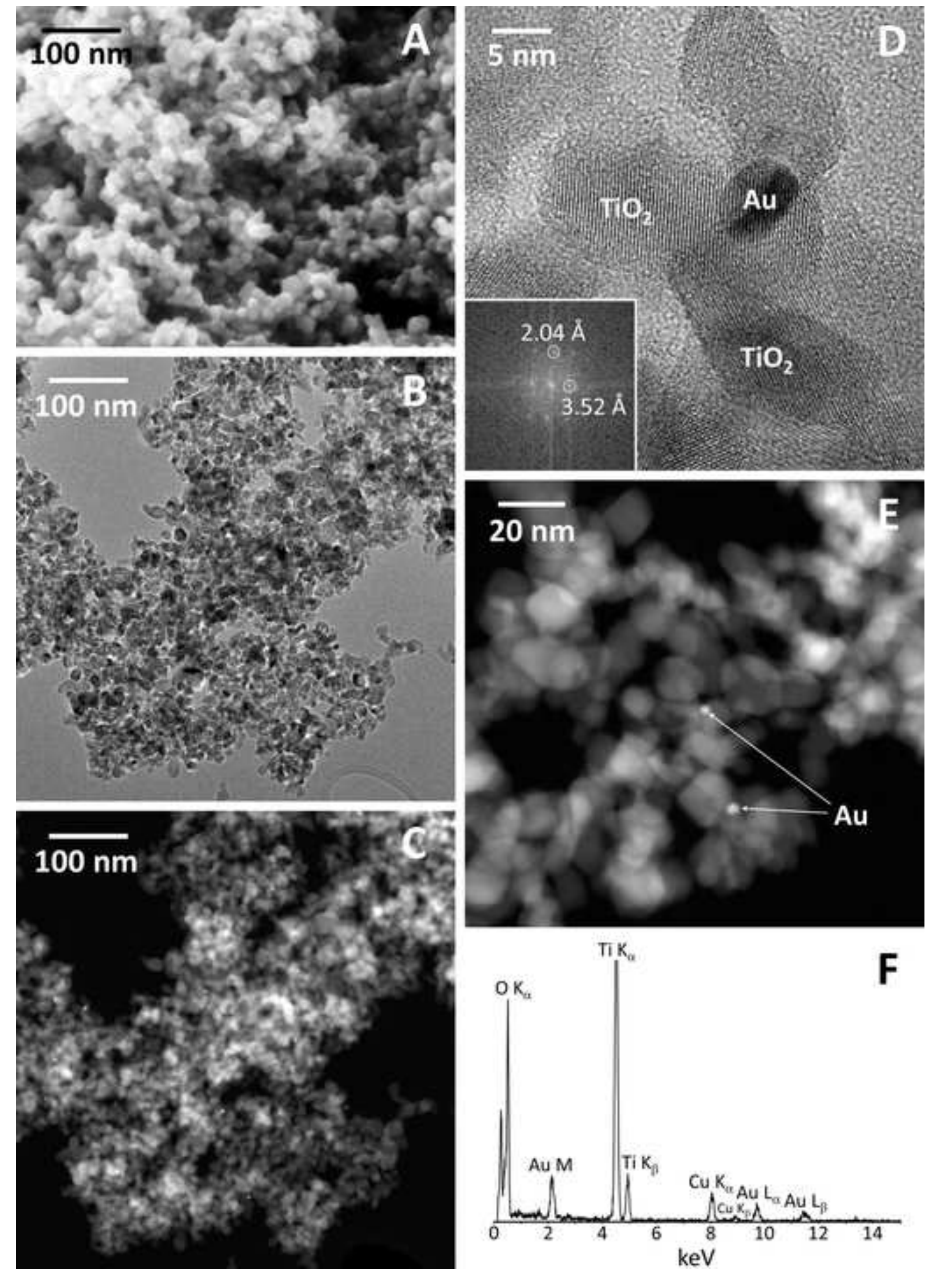


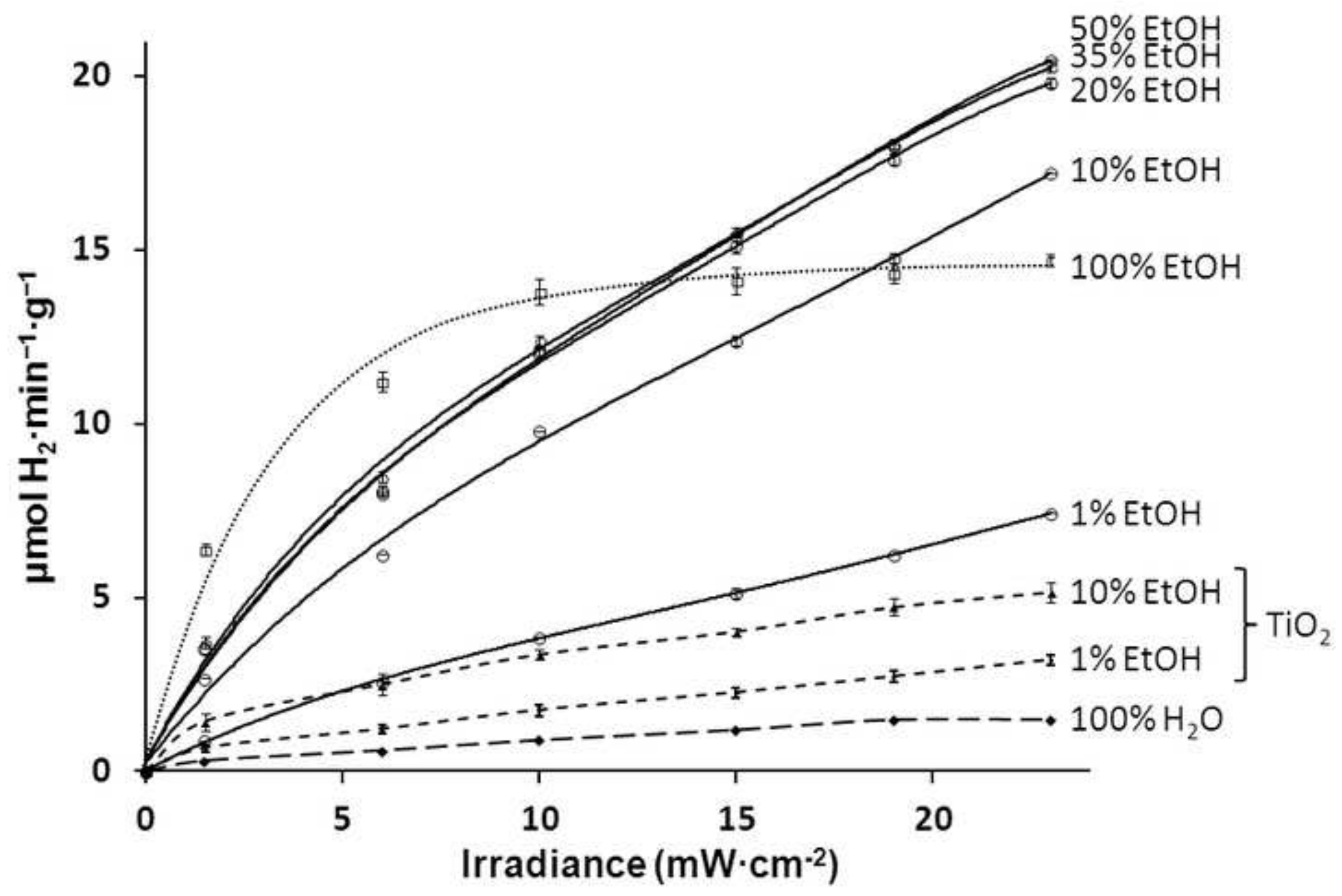




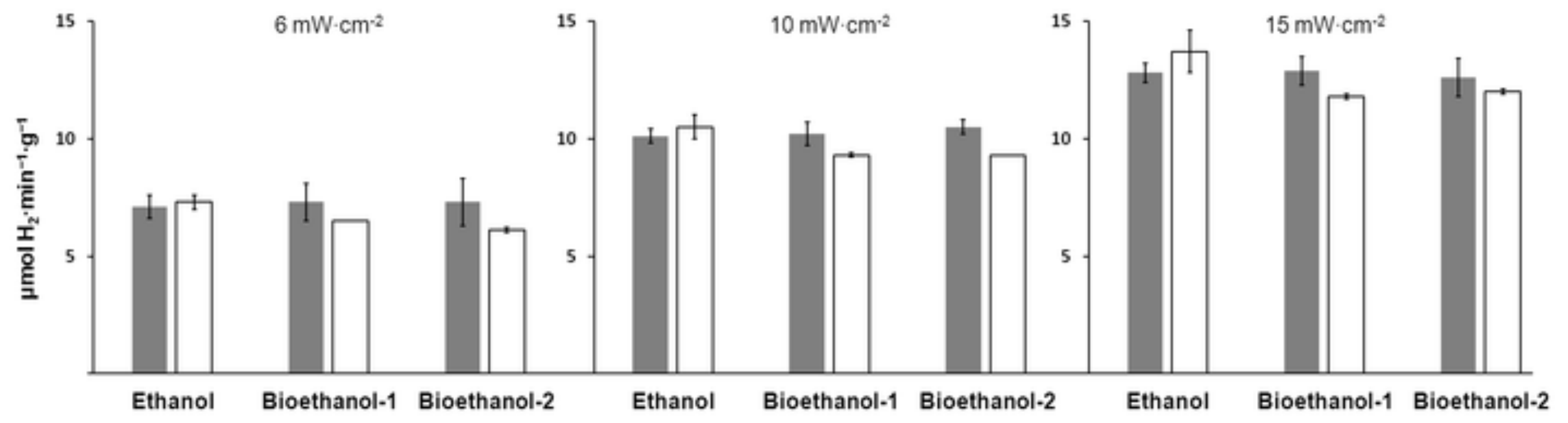




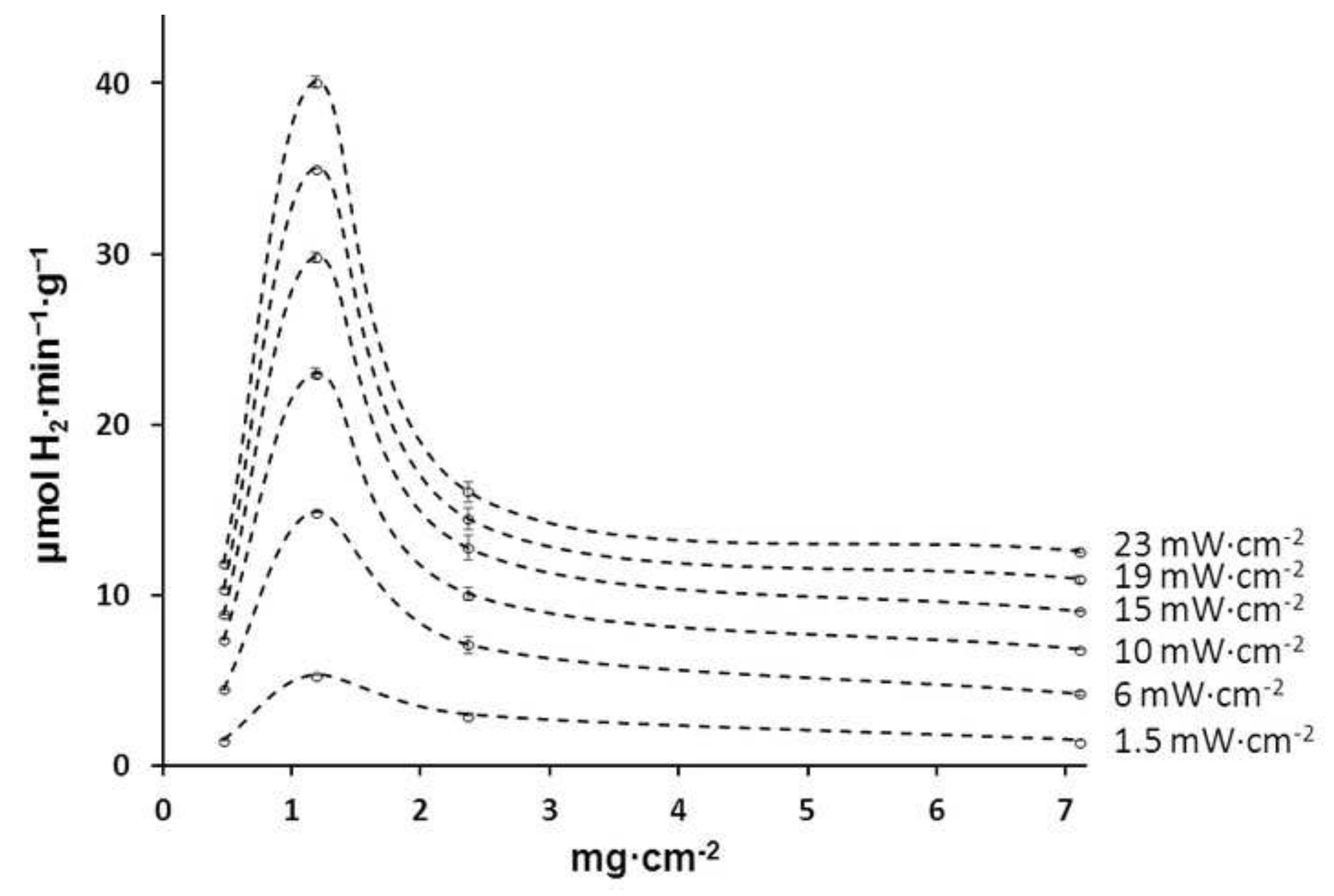




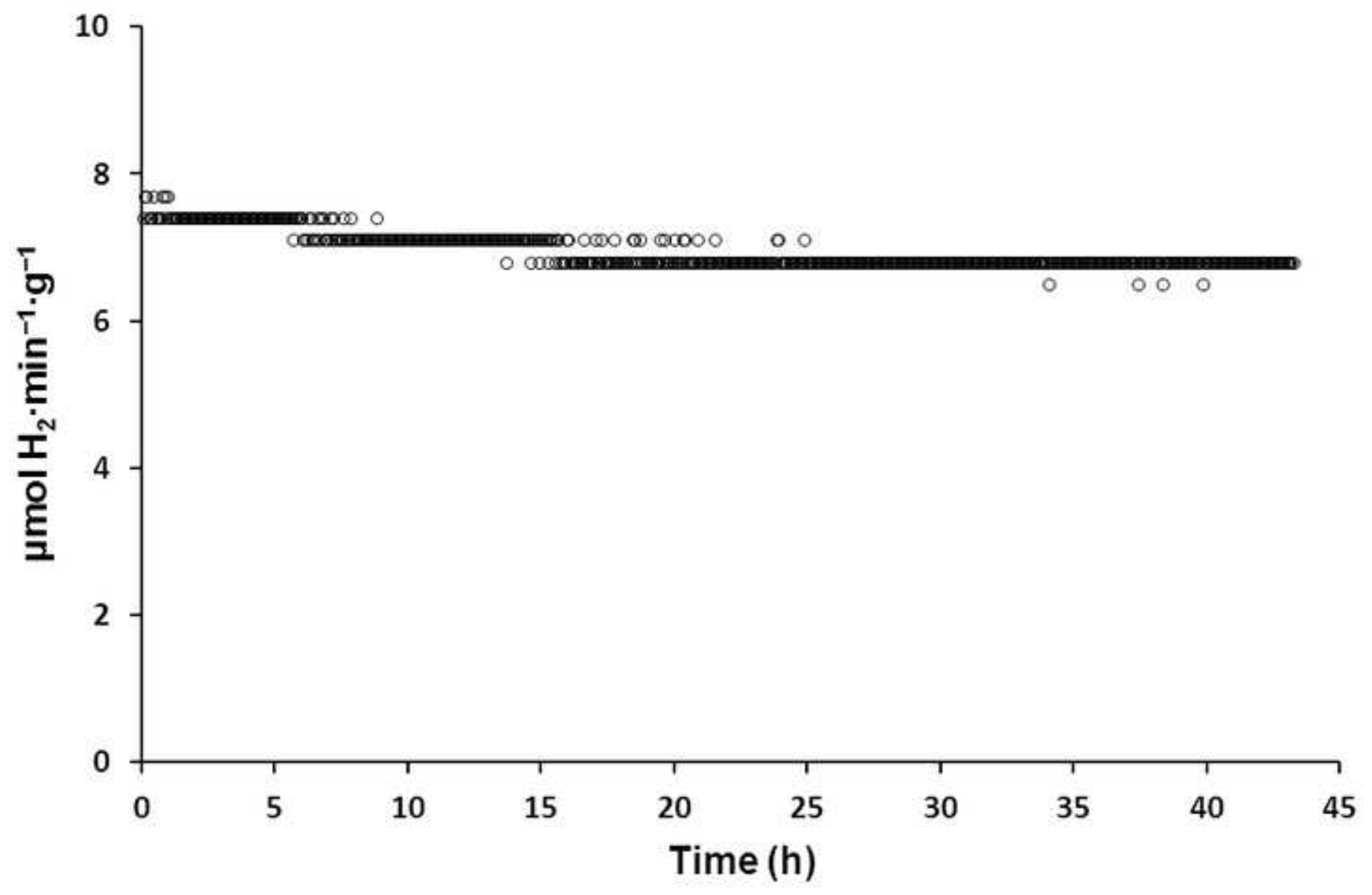

